\title{
Morphometric Study of Patella in Human Skeletons in Northeastern Brazil
}

\author{
João Pedro Maia Medeiros, ${ }^{1}$ Gustavo Henrique Cabral de Paula, ${ }^{1}$ Amanda do Nascimento Oliveira Carneiro, ${ }^{1}$ Desiré \\ Dominique Diniz de Magalhães, ${ }^{1}$ Matheus de Sousa Silva, ${ }^{2}$ André de Sá Braga Oliveira, ${ }^{1}$ Jalles Dantas de Lucena ${ }^{3}$ \\ ${ }^{1}$ Federal University of Paraiba - UFPB - João Pessoa - PB, Brazil \\ ${ }^{2}$ Federal University of Ceará - UFC - Fortaleza, CE, Brazil \\ ${ }^{3}$ College Santa Maria - FSM - Cajazeiras, PB, Brazil
}

Disclose and conflicts of interest: none to be declared by all authors

\section{ABSTRACT}

Introduction: the patella is a bone located in thickness of the tendon of the quadriceps femoral muscle, being a constituent of the patellofemoral joint. Knowledge of its morphology is important to comprehend better the clinical and surgical conditions that affect this joint. The objective of the present study was to analyze the morphology of patella in human skeletons in a population in Northeastern Brazil.

Material and Methods: 59 patella in a population in Northeastern Brazil were analyzed. The quantitative analysis includes measurements of the medial articular facet and the lateral articular facet of the patella. Qualitatively, the parameters observed were the patella shape, the presence of emargination and the type of patella, based on the width of the articular facets (Types I, II or III). Values of $p<0,05$ were considered significant.

Results: the predominance of triangular shape in both sides (52.6\%). We have accounted $54.2 \%$ emarginated patella, with a higher frequency on the left side (64.5\%). There has been a higher amount of Type II (84.8\%) patella, in which the medial articular facet is considerably smaller than the lateral one. The mean width of the medial articular facet was $18.20 \pm 0.52 \mathrm{~mm}$ $(11.90-24.20 \mathrm{~mm})$ on the right side, and $18.71 \pm 0.51 \mathrm{~mm}(14.40-26.20 \mathrm{~mm})$ on the left side $(p=0.48)$, whereas the lateral articular facet mean width was $24.49 \pm 0.34 \mathrm{~mm}(20.80-27.70 \mathrm{~mm})$ on the right side, and $23.88 \pm 0.51 \mathrm{~mm}(17.20-29.60 \mathrm{~mm})$ on the left side $(p=0.33)$.

Conclusion: For the first time, the morphometry of the patella was observed and registried in a population in Northeastern Brazil. The overall predominance of patella in this population is a triangular shape, with emargination and Type II or B.

Keywords: Anatomy. Knee; Patella; Morphology; Brazil.

\section{Introduction}

Patella is a flat bone in the body situated anterior to the knee joint (KJ). This structure lies deep to the fascia lata and your base is roughened for the attachment of rectus femoris and vastus intermedius ${ }^{1}$. It also guides the forces of quadriceps femoris component to the patellar ligament, helping to protect deeper KJ anatomy and quadriceps tendon from frictional forces. Besides that, patella increases compressive forces in the extensor mechanisms providing stability to the $\mathrm{KJ}^{2}$.

This bone is subdivided in facets (anterior and posterior) and borders (superior, lateral and medial). The articular cartilage in the posterior facet of the patella is the thickest in the body and forms one part of the patellofemoral joint. Different shapes of patella can modify this cartilage and cause instability in this region $^{3}$.

This facets are considered like "fingerprints" of the knee. Anterior surface receives the insertion of the quadriceps tendon, reveals vascular orifices and vertical striations and your inferior third is enveloped by the patellar ligament. In the posterior surface we find two parts: the articular cartilage (superior) and a non-articulation (inferior) that serves as a site of attachment for the patellar ligament. Moreover, the superior part is subdivided into a lateral and medial facets separated by a vertical ridge $\mathrm{e}^{1,4,5}$.

Wibeeg $(1941)^{6}$ introduced the classification of articular facets types based on the dimensions of the widths of medial and lateral articular surfaces: type I (lateral and medial surfaces equated in size), type II (medial surface smaller than lateral) and type III (medial surface's almost inexistent). Each of these types make different contacts and forces with the femoral articular facet. Furthermore, some patella presents a concavity in proximal portion of the lateral margin named emargination? ${ }^{7}$.

Knowledge of this patella's morphology is crucial in diagnoses and surgical corrections for injuries or disorders in knee joint. Its dimensions are utilized for implant design and surgeries like knee arthroplasty and correction techniques of patellar ligament grafts for reconstruct of anterior cruciate ligament. Patella's contribution to the knee anatomy is crucial to understand the pathology and guarantee the success and functionality in this procedures $\mathrm{s}^{2,5,8}$.

This study was motivated by scarcity of studies in Brazilian literature about Patella's characteristics. 
According to this, the objective of the current study was to analyze the morphology of patella in human skeletons in a population in the Northeastern Brazil.

\section{Materials and Methods}

This research was approved by the Ethics Committee of Health Sciences Center of Federal University of Paraiba - UFPB (protocol number 12942019.8.0000.5188). A total of 59 patellas from dried human skeletons of unknown ethnicity without any bone degeneration, gross pathology, abnormality or infant conformation were analyzed. The structures were obtained from the Human Anatomy Laboratory of the Federal University of Paraiba (UFPB) and Federal University of Ceará (UFC), localized in Northeastern Brazil.

The first parameter observed was laterality (right and left). Then, the patella were classified according to its shape in triangular, oval, and irregular ${ }^{9}$ (Figure 1).

Afterwards, the bones were analyzed to identify the presence of emargination ${ }^{7}$ and the type of articular facet (Type I, II or III) ${ }^{6}$ (Figure 2).

For the quantitative analysis, the measurements of the medial articular facet (MAF) (Measure A) and the lateral articular facet (LAF) (Measure B) were taken (Figure 3).

The data was collected through a macroscopy evaluation and registered in a datasheet. Images were taken of all patellas. Measurements were made using digital caliper (Eccofer $\AA$, João Pessoa, Paraíba, Brazil) with an accuracy of $0.01 \mathrm{~mm}$. Student's t-test was applied to evaluate differences between right and left antimeres using GraphPad Prism ${ }^{\circledR}$ version 6.00 for Windows, GraphPad Software, USA. Values of $\mathrm{p} \leq 0.05$ were considered significant.

\section{Results}

Among the 59 patellas analyzed, 28 (47.45\%) were right and 31 (52.55\%) were left patella. None was excluded. About the patella's classification, three shapes were observed: 31 (52.6\%) were triangular shape $(45.16 \%$ on the right side, and $54.84 \%$ on the left side); 16 (27.1\%) were oval (56.25\% on the right side, and $43.75 \%$ on the left side) and 12 (20.3\%) were irregular (41.67\% on the right, and $58.33 \%$ on the left) (Table 1).

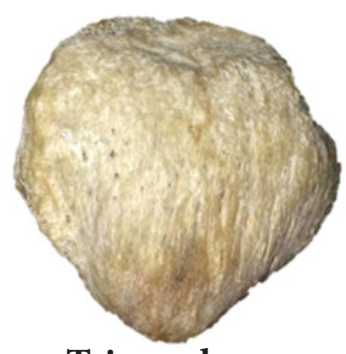

Triangular

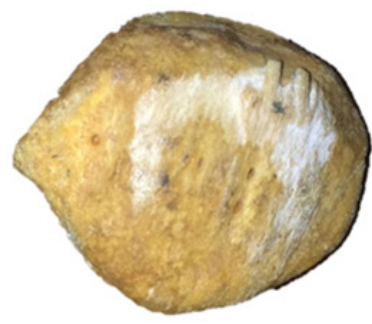

Oval

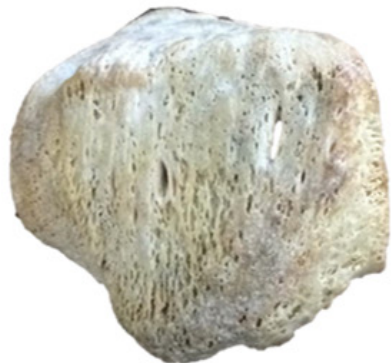

Irregular

Figure 1. Classification of patella's shapes by Goss (1988). Anterior view. (Collection Research)

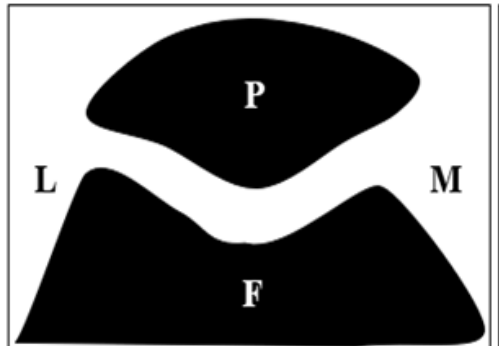

TYPE I

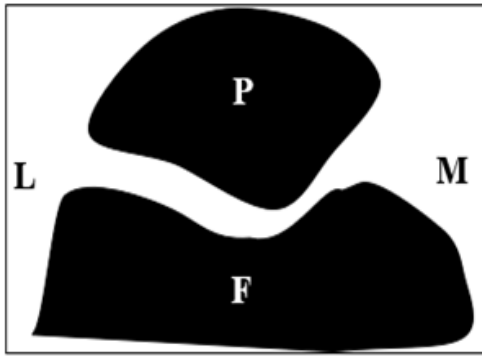

TYPE II

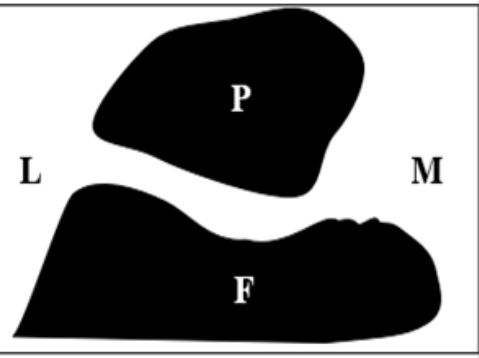

TYPE III

Figure 2. Classification of the type of articular face by Wibeeg (1941) ${ }^{6}$. Axial view. P- patella articular surface; F- femoral articular face; L- lateral; M- medial

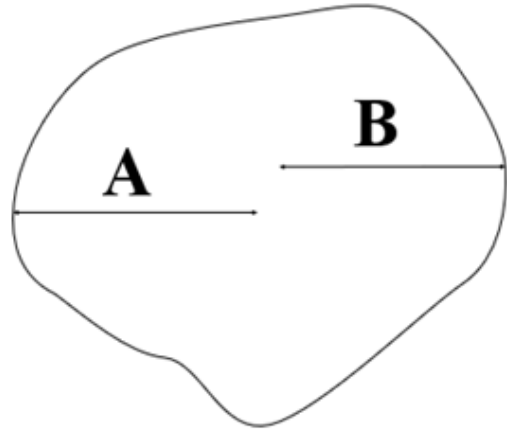

Figure 3. Measures of articular surface in a right patella. Posterior view. A-Medial articular facet measure (MAF); B- Lateral articular facet measure (LAF). (Collection Research)
Table 1. Patellar's shape percentage in both sides. $\mathrm{N}=59$

\begin{tabular}{l|c|c|c}
\hline Patellar Shape & Right side & Left side & Total \\
\hline Triangular & $14(50 \%)$ & $17(54.8 \%)$ & $31(52.6 \%)$ \\
\hline Oval & $9(32.2 \%)$ & $7(22.6 \%)$ & $16(27.1 \%)$ \\
\hline Irregular & $5(17.8 \%)$ & $7(22.6 \%)$ & $12(20.3 \%)$ \\
\hline Total & $28(100 \%)$ & $31(100 \%)$ & $59(100 \%)$ \\
\hline
\end{tabular}


Emargination was observed in 32 (54.2\%) patella, being more prevalent on the left side (Table 2). Analyzing the articular facet types, it was observed that type II was predominant in the sample with 50 patella (84.8\%), presenting an equal percentage between the sides. Type I had a minor prevalence (15.2\%) and type III patella were not found in this study (Table 3).

Table 2. Prevalence of patellar emargination in both sides. $\mathrm{N}=59$

\begin{tabular}{l|c|c|c}
\hline $\begin{array}{c}\text { Patellar } \\
\text { Emargination }\end{array}$ & Right side & Left side & Total \\
\hline Yes & $12(42.8 \%)$ & $20(64.5 \%)$ & $32(54.2 \%)$ \\
\hline No & $16(57.2 \%)$ & $11(35.5 \%)$ & $27(45.8 \%)$ \\
\hline Total & $28(100 \%)$ & $31(100 \%)$ & $59(100 \%)$ \\
\hline
\end{tabular}

Table 3. Articular surface's type in both sides. $\mathrm{N}=59$

\begin{tabular}{l|c|c|c}
\hline $\begin{array}{l}\text { Type of articular } \\
\text { surfaces }\end{array}$ & Right side & Left side & Total \\
\hline Type I & $3(10.7 \%)$ & $6(19.4 \%)$ & $9(15.2 \%)$ \\
\hline Type II & $25(89.3 \%)$ & $25(80.6 \%)$ & $50(84.8 \%)$ \\
\hline Type III & $0(0 \%)$ & $0(0 \%)$ & $0(0 \%)$ \\
\hline Total & $28(100 \%)$ & $31(100 \%)$ & $59(100 \%)$ \\
\hline
\end{tabular}

The mean value of the medial articular facet (MAF) was $18.47 \pm 0.36 \mathrm{~mm}$ between the sides, $(18.20 \pm 0.52 \mathrm{~mm}$ on the right side and $18.71 \pm 0.51 \mathrm{~mm}$ on the left side). The mean value of the lateral articular facet (LAF) was $24.17 \pm 0.31 \mathrm{~mm}$ between the sides $(24.49 \pm 0.34 \mathrm{~mm}$ on the right side and $23.88 \pm 0.51 \mathrm{~mm}$ on the left side (Table 4 ). No differences between the right and left sides were found in all parameters analyzed ( $p>0.05)$.

\section{Discussion}

The patella is the largest sesamoid bone in the body ${ }^{1,10}$. It is also an important component in the extensor mechanism of the knee joint, since it works as a lever to the quadriceps muscle, increasing its contraction force 4 . Moreover, it has a protective function against anterior knee trauma and provides an esthetic display as well.

Therefore, acknowledging that the anatomy of the knee joint displays a major role in the comprehension of how some pathologies work, such as the patellofemoral joint arthritis ${ }^{1}$, the Osgood-Schlatter disease ${ }^{11}$ and patellar dislocations or fractures, it is crucial to analyze the parameters that were presented in this study.

Also, some surgical approaches rely deeply on the orthopedic surgeon knowledge of the patella anatomy, with a frequent complication in a total knee arthroplasty procedure being the patellar lesion ${ }^{12}$, which can be minimized with refined technique and proper anatomical dominance ${ }^{13}$.

The present study has used the direct cadaveric approach to observe the measurements taken, while others have utilized data collected through a knee arthroplasty surgery or even radiological images, such as CT and MRI. The exams method may have some advantages, such as a limited number of cadaveric species, although this study has even more subjects analyzed than an expressive part of the literature. It may also present some downsides, such as the need to make some assumptions 5 .

In our study, the triangular shape was demonstrated to be the most prevalent one with 31 (52.6\%) of the patella, which corroborates with Goss description ${ }^{9}$, as the author states that this is the normal aspect of patella, presenting three straight margins, a larger superior one and two sides converging to the apex.

Also, this is the predominant shape in most studies, but in a considerably higher amount, such as Calderon et al. ${ }^{7}$, who has described a 51 (67.1\%) total of triangular patella, Borges et al. ${ }^{14}$, whose sample presented a total of $25(67.6 \%)$ specimens of this variant, and Chhaparwal et al. ${ }^{15}$, that identified $41(82 \%)$ patella of this shape (Table 5).

Table 4. Mean $(\mathrm{mm}) \pm \mathrm{SE}$ of patellar measures in both sides. $\mathrm{N}=59$

\begin{tabular}{l|c|c|c|c|c|c}
\hline & \multicolumn{2}{|c|}{ Right side } & \multicolumn{2}{c}{ Left side } & \multicolumn{2}{c}{ Total } \\
\hline Parameters & Min-Max & Mean (SE) & Min-Max & Mean (SE) & Mean (SE) & $p$-value \\
\hline MAF & $11.90-24.20$ & $18.20 \pm 0.52$ & $14.40-26.20$ & $18.71 \pm 0.51$ & $18.47 \pm 0.36$ & 0.48 \\
\hline LAF & $20.80-27.70$ & $24.49 \pm 0.34$ & $17.20-29.60$ & $23.88 \pm 0.51$ & $24.17 \pm 0.31$ & 0.33 \\
\hline
\end{tabular}

N: Number; Min: Minimum; Max: Maximum; SE: Standard error; MAF: Medial articular facet; LAF: Lateral articular facet.

Table 5. Comparative analysis of patella shape.

\begin{tabular}{l|l|l|l|l}
\hline \multicolumn{1}{c|}{ Population } & \multicolumn{1}{c|}{ Triangular } & \multicolumn{1}{c|}{ Oval } & \multicolumn{1}{c}{ Irregular } & \multicolumn{1}{c}{ Total } \\
\hline Calderon et al, 20127 Maringá, Brazil & $51(67.1 \%)$ & $12(15.8 \%)$ & $13(17.1 \%)$ & $76(100 \%)$ \\
\hline Borges et al, 2016 ${ }^{14}$, Ribeirão Preto, Brazil & $25(67.6 \%)$ & $8(21.6 \%)$ & $4(10.8 \%)$ & $37(100 \%)$ \\
\hline Chhaparwal et al, 2018 ${ }^{15}$, Indore, India & $41(82 \%)$ & $6(12 \%)$ & $3(6 \%)$ & $50(100 \%)$ \\
\hline Present study, Brazil & $31(52.6 \%)$ & $16(27.1 \%)$ & $12(20.3 \%)$ & $59(100 \%)$ \\
\hline
\end{tabular}


On the other hand, the present study has shown a notable larger amount of oval shape, representing a total of $16(27.1 \%)$ specimens, against only 12 (15.8\%), $8(21.6 \%)$, and $6(12 \%)$ shown in the other mentioned studies, respectively ${ }^{7,14,15}$. We have identified a higher prevalence of irregular shaped patella as well (Table 5).

Considering that both Brazilian studies ${ }^{7,14}$ take place in the same country of this present study, but in distant regions, the difference brought by this research might improve the professionals overall knowledge on how to approach the structure, due to its more frequent anatomical variation.

Another aspect that may be observed in the patella is the presence of emargination, which can be defined as a concavity in the proximal portion of the lateral margin, as defined by Kahle et al. ${ }^{16}$. The present study has identified 32 (54.2\%) patella with such aspect, with a slight superior prevalence on the left side. The referred aspect was also discussed in Calderon et al. ${ }^{7}$, who has published a significantly inferior presence of emarginated patella, with 23 exemplars, corresponding to $30.2 \%$ of its total sample.

This characteristic may appear due to ossification problems. Therefore, the higher prevalence of this aspect should alert professionals about the embryological process of bone formation, whereas might also propose a different approach in some procedures, such as the lateral collateral ligament (LCL) reconstruction, since the orthopedic surgeon that deals with a specific population as the one presented in this study may have an increased chance of dealing with a different anatomy, especially if using the patellar tendon allograft technique ${ }^{17}$.

The present study has also registered the analyzed sample according to the classification proposed by Wibeeg $^{6}$, where the author describes the patella as having 3 variants for the different facet sizes of the patela ${ }^{1}$, taking in consideration the width of the medial and the lateral articular facets, having the bone ridge as the point of reference. Each variant would present its own kind of forces and contact in the knee joint.

In the Type I, the ridge is located mostly in the center of the patella, resulting in the medial and lateral facets to be equal in size and both concaves. As for Type II, the width of the lateral facet is shortly superior to the one seen in the medial facet, which is a little bit convex, once the ridge is slightly dislocated towards the medial border of the patella. Finally, Type III presents a nearly indistinctive medial facet, in spite of the ridge being greatly displaced medially of the bone ${ }^{6}$.

In regard to this classification, the type II patella is overall the most common one in most literature reports, including Wibeeg $(1941)^{6}$ itself and this present study. While the original author has found 21 out of 25 (84\%) patella with the lateral articular facet slightly larger, this study recorded 50 out of 59 (84.8\%) specimens analyzed to present this conformation as well. Moreover, Calderon et al. (2012) ${ }^{7}$ has also reported an $85.5 \%$ of Type II patella, with 65 among a 76 total group of bones studied (Table 6).

Another author whose work has confirmed our findings was Reider et al. (1981)2 ${ }^{2}$, although his results were somewhat inferior, with a $57 \%$ (27 out of 48 ) prevalence of Type II exemplars. The main difference brought by this research was the high amount of Type III patella among its sample with 9 (19\%) examples, whereas the present study has identified none of this type, Wibeeg (1941) 6 has mentioned only 1 (4\%) and Calderon et al. (2012) ${ }^{7}$ about 5 (6.6\%) (Table 6).

About the Type I, a clinical significance of this varied morphology was presented by Fucentese et al. $(2006)^{18}$, in which the author analyzed 44 MRI images and divided his specimens in two groups, whether they presented trochlear dysplasia or not. These inclusion criteria might have affected the general results, as it is the only one with overall different proportions.

In the control group without this condition, out of 22 patients, 20 (90.9\%) had Type I patella, while only 2 (9.1\%) presented Type II. On the other hand, in the study group where the trochlear dysplasia was present, 8 (36.7\%) Type I patella were identified, against 12 (54.5\%) Type II and 2 (9.15) Type III ${ }^{18}$.

Therefore, Type II and III patella (lateral articular facet wider than medial articular facet) are more frequent in this pathology than the Type I, which was far more frequent in the group without trochlear dysplasia. This indicates that the morphology of the patella is directly representative in harmful conditions, reinforcing this study significance once again. Also, in populations where the Type I is more frequent, such as Reider et al. $(1981)^{2}$ this kind of

Table 6. Pattela types in different populations, Wibeeg $\mathrm{s}^{6}$ classification.

\begin{tabular}{l|c|c|c|c}
\hline \multicolumn{1}{c|}{ Population } & Type I & Type II & Type III & Total \\
\hline Wibeeg et al, 19416, Stockholm, Sweden & $3(12 \%)$ & $21(84 \%)$ & $1(4 \%)$ & $25(100 \%)$ \\
\hline Calderon et al, 20127, Maringá, Brazil & $6(7.9 \%)$ & $65(85.5 \%)$ & $5(6.6 \%)$ & $76(100 \%)$ \\
\hline Reider et al, 19812, New York, USA & $12(24 \%)$ & $27(57 \%)$ & $9(19 \%)$ & $48(100 \%)$ \\
\hline Fucentese et al, 2006 ${ }^{18}$, Berlin Germany & $28(63.63 \%)$ & $14(31.18 \%)$ & $2(4,5 \%)$ & $44(100 \%)$ \\
\hline Present study, Brazil & $9(15.9 \%)$ & $50(84.8 \%)$ & $0(0 \%)$ & $59(100 \%)$ \\
\hline
\end{tabular}


condition may be less prevalent.

Another classification proposed throughout the years for the patella according to the width of the articular facets was developed by Koyuncu et al. (2011) ${ }^{3}$. The main difference in the methodology adopted by this author was the observation of the morphometry of the patella during the fetal period, which led the study to propose a new classification, in order to embrace its new findings.

In this new method, Type A corresponds to the equality of both articular facets in width, same thing as observed in Wibeeg (1941) 6 Type I. As for Type B, the medial articular facet is smaller, just like Type II and III in the previous scale. Finally, the difference is perceived in Type $\mathrm{C}$ patella, where the lateral articular facet is actually the smaller one. This final variant is absent in the previously mentioned classification.

The discussion here takes an interesting level since Koyuncu et al. (2011) ${ }^{3}$ have described a total of 64 (30.5\%) units of Type C patella. Even though Type B was still the most prevalent kind of bone identified with a total of 105 (50\%), corroborating with the previous discussed results, posterior studies who have used the same scale failed to identify such high amount of Type $\mathrm{C}$ among the individual studied (Table 7).

For instance, Olateju et al. (2013) ${ }^{5}$ described 40 (87\%) Type B species and has found only one (2\%) Type C in his sample. Also, Murugan et al. (2017) ${ }^{19}$ could not identify any Type $\mathrm{C}$ patella, while also describing 58 (89.2\%) Type B individuals. Finally, Chhaparwal et al. $(2018)^{15}$ has found 41 (82\%) Type B patella, without any description of Type $\mathrm{C}$ bones as well (Table 7).

The present study, as discussed previously, identified $50(84.8 \%)$ correspondents of the Type B, without any presence of the ones described as Type $\mathrm{C}$ (Table 7).

Hence, after observing the results brought by Koyuncu et al. (2011) ${ }^{3}$, who described the patella morphology throughout the fetal period, and the different pattern shown in the other studies, whose sample was composed mostly or entirely by adults, there is a notable change in prevalence of the Type $C$ patella, with a high amount of individuals presenting such variant in the gestational period and almost none in dry patella or image exams. Therefore, this may suggest that our patella goes through a process of remodeling in its articular surface as years go by in extra uterus life.

Finally, the last registered parameters were the measurements of the width of the medial articular facet and the lateral articular facet, composing the quantitative analysis. As mentioned in the results section, the MAF presented a mean width of $18.47 \pm 0.36$ $\mathrm{mm}$, whereas the value for the LAF was registered as $24.17 \pm 0.31 \mathrm{~mm}$. There was no statistically significant difference between the right or left sides patella $(p>0.05)$ (Table 4). These results are expected in a higher prevalent Type II or Type B sample such as ours.

These measures are slightly divergent in the literature reports, since different populations may present an overall change in stature, which is identified in the reports, but also because many authors decide to make distinct subgroups for their results.

For example, the present study has not found statistically significant difference between sides in these measurements, as mentioned earlier, just like the report published by Chhaparwal et al. (2018) ${ }^{15}$ and by Shang et al. (2014) ${ }^{20}$, which reinforces our conclusions that the side of the patella does not directly affect its morphology (Table 8).

On the other hand, Baldwin and House $(2005)^{12}$, Olateju et al. (2013) $)^{5}$ and also Shang et al. $(2014)^{20}$ were able to describe a variant morphometry in different sexes, with both MAF and LAF mean width values being superior in males.

Additionally, other studies corroborate with the higher measures described in male individuals, such as Schlenzka and Schwesinger (1990) ${ }^{21}$, Yoo et al. (2007) ${ }^{22}$, Iranpour et al. (2008) ${ }^{23}$, and Jain et al. (2019) ${ }^{24}$, although they do not distinguish the measures of both articular facets, only describing the general width of the patella.

Heading back to the number's comparison, we do not see much difference in the articular facets measures, only a slightly inferior value for the MAF in the present study and a somewhat superior width of the LAF in the American population. The values reflect the vast predominance of Type B patella, with the LAF measures being notably superior. The interesting clinical relation goes to the earlier mentioned Study Group with Trochlear dysplasia in Fucentese et al. (2006) ${ }^{18}$ work, linking this pathology to a smaller MAF in comparison to the healthy control group (Table 8).

Table 7. Pattela types in different populations, Koyuncu's $\mathrm{s}^{3}$ classification.

\begin{tabular}{l|c|c|c|c}
\multicolumn{1}{c|}{ Population } & Type A & Type B & Type C & Total \\
\hline Koyuncu et al, $2011^{3}$, Isparta, Turkey & $41(19.5 \%)$ & $105(50 \%)$ & $64(30.5 \%)$ & $210(100 \%)$ \\
\hline Olateju et al, $2013^{5}$, Johannesburg, South Africa & $5(11 \%)$ & $40(87 \%)$ & $1(2 \%)$ & $46(100 \%)$ \\
\hline Murugan et al, $2017^{19}$, Pondicherry, India & $7(10.8 \%)$ & $58(89.2 \%)$ & $0(0 \%)$ & $65(100 \%)$ \\
\hline Chhaparwal et al, 2018 ${ }^{15}$, Indore, India & $9(18 \%)$ & $41(82 \%)$ & $0(0 \%)$ & $50(100 \%)$ \\
\hline Present study, Brazil & $9(15.9 \%)$ & $50(84.8 \%)$ & $0(0 \%)$ & $59(100 \%)$ \\
\hline
\end{tabular}


Table 8. Mean width $(\mathrm{mm}) \pm$ Standard Deviation (SD) of the articular facets in different populations.

\begin{tabular}{|c|c|c|}
\hline Population & Medial Articular Facet & Lateral Articular Facet \\
\hline Chhaparwal et al, $2018^{15}$, Indore, India & $20.70(1.89)$ & $23.36(2.23)$ \\
\hline Shang et al, $2014^{20}$, Shenzhen, China & $19.03(2.21)$ & $25.10(2.77)$ \\
\hline Olateju et al, $2013^{5}$, Johannesburg, South Africa & $20.38(3.36)$ & $26.02(2.68)$ \\
\hline Fucentese et al, 2006 ${ }^{18}$, Berlin Germany ${ }^{\mathrm{a}}$ & $18.73(3.57)$ & $25.55(2.31)$ \\
\hline Fucentese et al, $2006^{18}$, Berlin Germany ${ }^{b}$ & $22.82(4.17)$ & $25.50(2.46)$ \\
\hline Baldwin and House, $2005^{12}$, Portland, USA & 20.5 & 27.5 \\
\hline Present study, Brazil & $18.47(0.36)$ & $24.17(0.31)$ \\
\hline
\end{tabular}

a Values of the Study Group with Trochlear dysplasia.

b Values of the Control Group without Trochlear dysplasia.

The final point of the discussion is the patella width mean value and its direct correlation with the group of people in which they were observed. For example, Southern Asians have presented the smallest patellas in general, with corresponding studies in India and South China. Then, British and American citizens have a slightly wider patella, with the Northern European population in Finland being the ones with the higher values shown (Table 9).

In conclusion, this is an additional evidence of the massive importance of describing this information in anatomical and anthropological studies, to reinforce our varied morphometry throughout the world (Table 9).

\section{Conclusion}

For the first time, the morphometry of the patella was observed and registried in a population in Northeastern Brazil, including a full research with anthropological comparisons about the shape, the presence of emargination, the type and the measurements of this structure.

The overall predominance of patella in this population is a triangular shape, with emargination and Type II or B. The study found no significant difference between the left and the right side as for the measures of the medial and lateral articular facets.

These identifications corroborate with several findings in the literature, although some of the values are proportionally different, which should led to a more detailed approach by the health care professionals, such as orthopedic surgeons, sports doctors, physiotherapists, and nurses, for example.

Therefore, when performing procedures like a total knee arthroplasty or replacing knee prosthesis, it is fundamental to dominate the anatomy of the knee joint, including the patella morphology. Also, this knowledge helps to elucidate the physiopathology of several diseases, with the examples of the trochlear dysplasia, patellofemoral joint arthritis, the OsgoodSchlatter disease and patellar dislocations or fractures.

Table 9. Mean width $(\mathrm{mm}) \pm$ Standard Deviation (SD) of patella in different populations.

\begin{tabular}{|c|c|}
\hline Population & Mean width \\
\hline Murugan et al, $2017^{19}$, Pondicherry, India & $38.58(3.81)$ \\
\hline Chhaparwal et al, $2018^{15}$, Indore, India & $38.67(3.41)$ \\
\hline Jain et al, 2019²4, Rishikesh, India & $43.35(4.10)$ \\
\hline Shang et al, $2014^{20}$, Shenzhen, China & $44.13(3.96)$ \\
\hline Iranpour et al, $2008^{23}$, London, UK & $44.8(4.80)$ \\
\hline Yoo et al, $2007^{22}$, Seoul, South Korea & $45.8(3.6)$ \\
\hline Baldwin and House, $2005^{12}$, Portland, USA & 46.10 \\
\hline Reider et al, 1981², New York, USA & 47 \\
\hline Schlenzka and Schwesinger, 1990²1, Helsinki, Finland & $50.3(4.0)$ \\
\hline Present study, Brazil & $42.64^{\mathrm{a}}$ \\
\hline
\end{tabular}

a This value was calculated from the mean width of both articular facets. 


\section{References}

1. Fox AJ, Wanivenhaus F, Rodeo SA. The basic science of the patella: structure, composition, and function. J Knee Surg 2012;25:127-41.

2. Reider B, Marshall JL, Koslin B, Ring B, Girgis FG. The anterior aspect of the knee joint. J Bone Joint Surg Am 1981;63:351-6.

3. Koyuncu E, Cankara N, Sulak, O, Özgüner G, Albay S. The morphometry of patella and patellar ligament during the fetal period. Clin Anat 2011;24:225-31.

4. Grelsamer RP, Weinstein CH. Applied biomechanics of the patella. Clin Orthop Relat Res 2001;389:9-14.

5. Olateju OI, Philander I, Bidmos MA. Morphometric analysis of the patella and patellar ligament of South Africans of European ancestry. S Afr J Sci 2013;109:01-06.

6. Wibeeg G. Roentgenographs and Anatomic Studies on the Femoropatellar Joint: With Special Reference to Chondromalacia Patellae. Acta Orthop Scaud 1941;12:319-410.

7. Calderon KA, Inhoti PA, Bertolini SMMG. Anatomia da Patela de Esqueletos Humanos. Saúde e Pesquisa 2012;5:97-103.

8. Miller TT, Staron RB, Feldman F. Patellar height on sagittal MR imaging of the knee. AJR Am J Roentgenol 1996;167:339-41.

9. Goss CM. Gray Anatomia. 29th ed. Rio de Janeiro: Guanabara Koogan; 1988.

10. Drake RL, Vogl AW, Mitchel A. Gray's: Anatomia para estudantes. 2th ed. Rio de Janeiro: Elsevier, 2005.

11. Circi E, Atalay Y, Beyzadeoglu T. Treatment of Osgood-Schlatter disease: review of the literature. Musculoskelet Surg 2017;101:195-200. 12. Baldwin JL, House CK. Anatomic Dimensions of the Patella Measured During Total Knee Arthroplasty. J Arthroplasty 2005;20:250-7.

13. Mont MA, Yoon TR, Krackow KA, Hungerford DS. Eliminating Patellofemoral Complications in Total Knee Arthroplasty: Clinical and Radiographic Results of 121 Consecutive Cases Using the Duracon
System. J Arthroplasty 1999;14:446-55.

14. Borges CAS, Carvalho AT, Júnior VM, Savoldi M, Bim WR, Fazan VPS. Morphological classification and dimensions of the human patella. The FASEB Journal 2016;30:1_supplement, lb4-lb4.

15. Chhaparwal R, Hiware S, Chhaparwal P, Chhaparwal N. Morphometric study of Knee Cap (Patella). Ann Int Med Den Res 2018;4:5-9.

16. Kahle W, Leonhardt H, Platzer W. Atlas de Anatomia Humana. 3th ed. São Paulo: Atheneu, 1988.

17. Latimer HA, Tibone JE, ElAttrache NS, McMahon PJ. Reconstruction of the lateral collateral ligament of the knee with patellar tendon allograft. Report of a new technique in combined ligament injuries. Am J Sports Med 1998;26:656-62.

18. Fucentese SF, von Roll A, Koch PP, Epari DR, Fuchs B, Schottle PB. The patella morphology in trochlear dysplasia - A comparative MRI study. Knee 2006;13:145-50.

19. Murugan M, Ambika S, Nim VK. Knee Cap: a morphometric study. Int J Anat Res 2017;5:3556-59.

20. Shang $P$, Zhang L, Hou Z, Bai X, Ye X, Xu Z, et al. Morphometric measurement of the patella on 3D model reconstructed from CT scan images for the southern Chinese population. Chin Med J (Engl) 2014;127:96-101.

21. Schlenzka D, Schwesinger $G$. The height of the patella: an anatomical study. Eur J Radiology 1990;11:19-21.

22. Yoo JH, Yi SR, Kim JH. The geometry of patella and patellar tendon measured on Knee MRI. Surg Radiol Anat 2007;29:623-8.

23. Iranpour F, Merican AM, Amis AA, Cobb JP. The Width: thickness Ratio of the Patella. Clin Orthop Relat Res 2008;466:1198-1203.

24. Jain R, Kalia RB, Das L. Anthropometric measurements of patella and its clinical implications. Eur J Orthop Surg Traumatol 2019;29:1765-9. 